\title{
Comunicación

\section{Tendencias, rupturas, constantes y cambios: 20 años de Comunicación y Sociedad}

Con este número, Comunicación y Sociedad cumple 20 años de aparición ininterrumpida como vehículo de diálogo y debate entre los miembros del campo académico de la comunicación social. La historia de la revista, contada de manera acuciosa tanto en el espacio del número 30 de la primera etapa de la publicación (mayo-agosto 1997), como en el primer ejemplar de la nueva época (enero-junio 2004), nos muestra que a lo largo de sus dos décadas, Comunicación y Sociedad ha sido un escaparate privilegiado de las tendencias, preocupaciones e intereses de investigación prevalecientes en México, Iberoamérica y el mundo anglosajón. La distinción se sustenta por igual en la calidad de las colaboraciones difundidas y en la circunstancia de que, precisamente, estos 20 años (la última década del siglo XX y la primera del XXI) han concentrado la mayor cantidad de transformaciones en los entornos político, económico, tecnológico y jurídico de las prácticas de comunicación social de este mundo "desbocado", apresurado y globalizado. ¿Cuál ha sido la constante durante esta vasta experiencia de diálogo científico? Sin duda alguna, el cambio, la perplejidad, la incertidumbre.

El número 8 de Comunicación y Sociedad se compone de siete artículos y cuatro reseñas, conjunto que constituye una muestra más de la búsqueda de modelos de análisis "más adecuados" para comprender

1 Coordinadora de este número de aniversario. Universidad de Guadalajara.

Correo electrónico: hernande@cencar.udg.mx 
una realidad que parece caracterizarse por la permanente reinvención de las prácticas de comunicación social; un cuestionamiento a conceptos "consagrados" y una descripción de algunos fenómenos poco observados, pese a su obvia presencia y a su relevancia social indiscutible.

En "Acceso y usos de internet en el occidente de México: el caso de Jalisco", Pablo Arredondo Ramírez analiza los resultados de una amplia encuesta realizada en 2006 sobre las tendencias predominantes de "consumo mediático" en la entidad, y se detiene particularmente en la penetración de internet y los usos más recurrentes que de ella hacen los internautas de esta región de México.

Francisco J. Martínez G., Eduardo García R. y Andrea Menchaca analizan los cambios y modificaciones legislativas que ha habido en México en relación con el cine y la televisión, a más de una década de la firma del Tratado de Libre Comercio, y presentan las repercusiones de estos cambios en la oferta y contenido audiovisual en México, de acuerdo con los resultados de un análisis de contenido. Empíricamente demuestran no sólo que el gobierno mexicano ha tenido en el abandono a la industria cinematográfica, y que ha seguido protegiendo a la de la televisión, sino también que los contenidos de la televisión mexicana, cuyo flujo se incrementa, tienden a reproducir los modelos de éxito en Norteamérica y Europa.

François Demers y Alain Lavigne nos acercan a la comprensión del concepto de "comunicación pública", adoptado a finales del siglo XX en la Universidad Laval de Quebec, como un auténtico concepto prometedor para investigar el contexto mediático de la "democracia del tercer tipo" y, por lo tanto, como una prioridad contemporánea de investigación. Los autores se refieren a los numerosos cambios en el funcionamiento de la oferta mediática de la época -con la emergencia de diarios gratuitos, de cadenas de televisión transfronteras de información continua, y de internet-, y sostienen que el ya veterano concepto de "espacio público" no es suficiente para el análisis.

Thomas Tufte construye una propuesta para operacionalizar la teoría de las mediaciones, en el análisis de la producción de sentido a nivel de audiencias. En su abordaje, el autor presenta el desenvolvimiento de los desarrollos teórico-metodológicos relacionados con la intervención social, y nos permite comprender con claridad su origen, direc- 
ción, aportes y limitaciones. Recupera y aplica la pedagogía dialógica de Freire en una intervención de E-E (entertainment-education), que nos indica cuáles han sido los avances y cuáles son los retos o desafíos a resolver en materia de estrategias de comunicación para el cambio social. El trabajo presenta a la etnografía de la audiencia, como propuesta analítica que relaciona los paradigmas para entender las formas en que los textos mediáticos interactúan y se vuelven parte de las prácticas sociales y culturales.

En "Flou, invención y ordinario del periodismo", Denis Ruellan nos habla del modelo de formación identitaria del periodismo en Francia: el professionnalisme du flou, un modelo cuya gestión del espacio y de las relaciones profesionales ha sido fluida $-\mathrm{y}$ profundamente pragmática. El autor da cuenta, también, de la pluralidad de discursos en torno al proceso continuo de construcción y de transformación de la identidad del grupo profesional, y confronta la mirada unívoca y esencialista del periodismo defendida por este grupo (una "práctica profesional"), con la perspectiva que considera al periodismo como una "práctica social" co-construida por una diversidad de actores interconectados en el corazón de un espacio público ampliado. Finalmente, el autor propone una nueva mirada de investigación que sugiere una renovación profunda de las problemáticas de los estudios sobre el periodismo.

Daniel Mato abre un interesante debate en torno al uso de categorías "consagradas" en los estudios culturales que obstruyen o limitan las posibilidades de investigación en los campos de la comunicación y la cultura: el uso de las categorías "industrias culturales" y "consumo cultural" destaca el atributo "cultural" de algunas industrias y consumos en particular, y oculta la relevancia cultural de todas las demás industrias y consumos. El autor profundiza particularmente en torno a las implicaciones epistemológicas y metodológicas que conlleva el término "industrias culturales", ofreciendo nuevas posibilidades de abordaje y algunas pautas de método al respecto.

En un escrupuloso trabajo desde la perspectiva jurídica, David Ramírez Plascencia documenta y examina el conflicto legal más importante de censura y regulación de internet que tuvo lugar en el año 2000: "El caso Yahoo!", paradigmático en las discusiones en torno a la normatividad internacional del ciberespacio, que pone a debate los aspectos de 
territorialidad, jurisdicción y libertad de expresión en la red de redes.

20 años de tendencias, de constantes, de rupturas y de cambios..., muchos años de Comunicación y Sociedad por venir, y una invitación a la comunidad académica para seguir dialogando en torno a las prioridades de investigación de nuestro campo, en este mundo cambiante y desafiante que demanda reflexión sobre nuestras prácticas como analistas de la comunicación y el papel que aquellas juegan en el debate social más amplio. 